\title{
Performance of Modified Silicon-Based Optical Leaky-Wave Antenna Structures
}

\author{
Ali A. Hummadi, R. S. Fyath \\ M.Sc. Searcher, College of Engineering, Alnahrain University, Baghdad, Iraq \\ Ali1988abbas@yahoo.com \\ Professor, College of Engineering, Alnahrain University, Baghdad, Iraq \\ rsfyath@yahoo.com
}

\section{ABSTRACT}

Conventional silicon-based optical leaky-wave antennas (OLWAs) have been investigated in the literature as high directivity narrow-beam radiators with steering capability and designed for $1550 \mathrm{~nm}$ operation using single-grating layer. In this paper, two modifications are introduced to the conventional silicon-based OLWA. The first modification is to redesign the structure for $1300 \mathrm{~nm}$ operation and to compare the radiation parameters with those of the $1550 \mathrm{~nm}$ counterpart. The second modification is to design and investigate the performance of a double-grating OLWA which is useful for doublebeam steering.

\section{Indexing terms/Keywords}

Optical leaky wave antenna (OLWA); Silicon-based antenna; Silicon optical antenna..

\section{Academic Discipline And Sub-Disciplines}

Electronics and Data Communications.

\section{SUBJECT CLASSIFICATION}

Optical antennas

\section{TYPE (METHOD/APPROACH)}

Simulation work.

\section{Council for Innovative Research}

Peer Review Research Publishing System

Journal: INTERNATIONAL JOURNAL OF COMPUTERS \& TECHNOLOGY

Vol. 14, No. 3

www.ijctonline.com , editorijctonline@gmail.com 


\section{INTRODUCTION}

Silicon-based photonics have generated nowadays a huge interest mainly for optical telecommunications and increasingly also for sensing The development of elementary passive and active components has reached such a performance level that the combination of these building blocks can lead to the development and the commercialization of high performance transceivers [1] This progress is mainly driven by the compactness of the integrated optical components and the fact that these devices can be fabricated using the mature complementary metal-oxide-semiconductor (CMOS) fabrication infrastructure, resulting in high yield and high volume fabrication [2]. In fact CMOS platform dominated the microelectronics industry in the last 40 over years through the enablement of complex low power electronic circuits with high yields. Silicon is a very good optical waveguide material for $1300 \mathrm{~nm}$ and $1550 \mathrm{~nm}$ wavelength regions (usually used in optical communications) because it is transparent beyond $1.1 \mu \mathrm{m}$ and has high refractive index contrast (with $\left.\mathrm{SiO}_{2}\right)$.

Recently, there is increasing interest to extend the concepts of microwave antennas to optical frequencies leading to optical antennas. These antennas have the ability to control the emission and scattering of light with a small-scale footprint [3-5]. For example, a novel silicon-based optical leaky-wave antenna (OLWA) has been proposed to provide very directive radiation at $1550 \mathrm{~nm}$ [6]. This wavelength has been used widely in optical communication systems since it corresponds to the minimum attenuation wavelength in standard single-mode silicon fibers. The structure is CMOS compatible and hence can be fabricated on silicon-on-insulator (SOI) platform which is suitable for both optoelectronic and photonic integration [7]. Further, the radiation parameters of the reported antenna can be controlled by introducing excess carriers in the silicon via electronic or optical injection [7,8]. The OLWA consists of $\mathrm{SiO}_{2}-\mathrm{Si}_{3} \mathrm{~N}_{4}-\mathrm{SiO}_{2}$ waveguide with silicon perturbations positioned on the bottom side of the silicon nitride core as shown in Fig.1. The structure is capable of radiating one main beam from the bottom side.

The effect of structure parameters on the far-field radiation of the $1550 \mathrm{~nm}$ OLWA proposed in [6] has been reported in the literature. Various radiation parameters are tracked during this parametric study such as scattering coefficients, radiation and total efficiencies, directivity, gain, main lobe magnitude and direction, side lobe level, and angular width of the main beam. The parametric study covers also the number of silicon perturbations, perturbation width, grating period, and the perturbation thickness. In this paper, the silicon-based OLWA is redesigned for $1300 \mathrm{~nm}$ operation and its performance is evaluated and compared with that of conventional counterpart operating at $1550 \mathrm{~nm}$. Further, the structure of the OLWA is modified to radiate two main beams simultaneously by inserting additional silicon perturbations on the top side of the core waveguide. The results are based mainly on simulations obtained using the commercial software CST (CST STUDIO SUITE 2013).

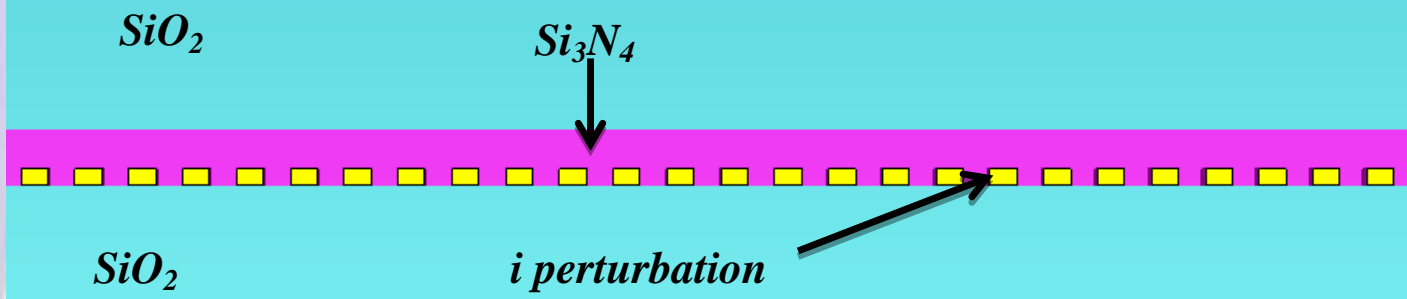

Fig. 1: Silicon-based optical leaky-wave antenna.

\section{2. $1300 \mathrm{~nm}$ Optical Leaky-Wave Antenna}

The structure under investigation is a single-grating antenna (SGA) similar to the structure shown in Fig. 1. The geometric parameters used in the design are waveguide thickness $h w=1000 \mathrm{~nm}$, thickness of the silicon bar $h=300 \mathrm{~nm}$, and the ratio of silicon bar width to perturbation grating period $w / d=0.5$. These values are similar to those adopted in the $1550 \mathrm{~nm}$ antenna design. However, the value of $d$ depends strongly on the operating wavelength and should be chosen carefully.

At $1300 \mathrm{~nm}$, the refractive indices of the materials used in the design are 3.5, 1.454, and 1.7 for $\mathrm{Si}_{1} \mathrm{SiO}_{2}$, and $\mathrm{Si}_{3} \mathrm{~N}_{4}$, respectively. Simulation results using CST yield an effective refractive index of 1.503 . Using eqn. 1 , the grating period $d$ is estimated to be $830 \mathrm{~nm}$ to achieve $\theta_{\text {shift }}=-2.5^{\circ}$. 
$d$

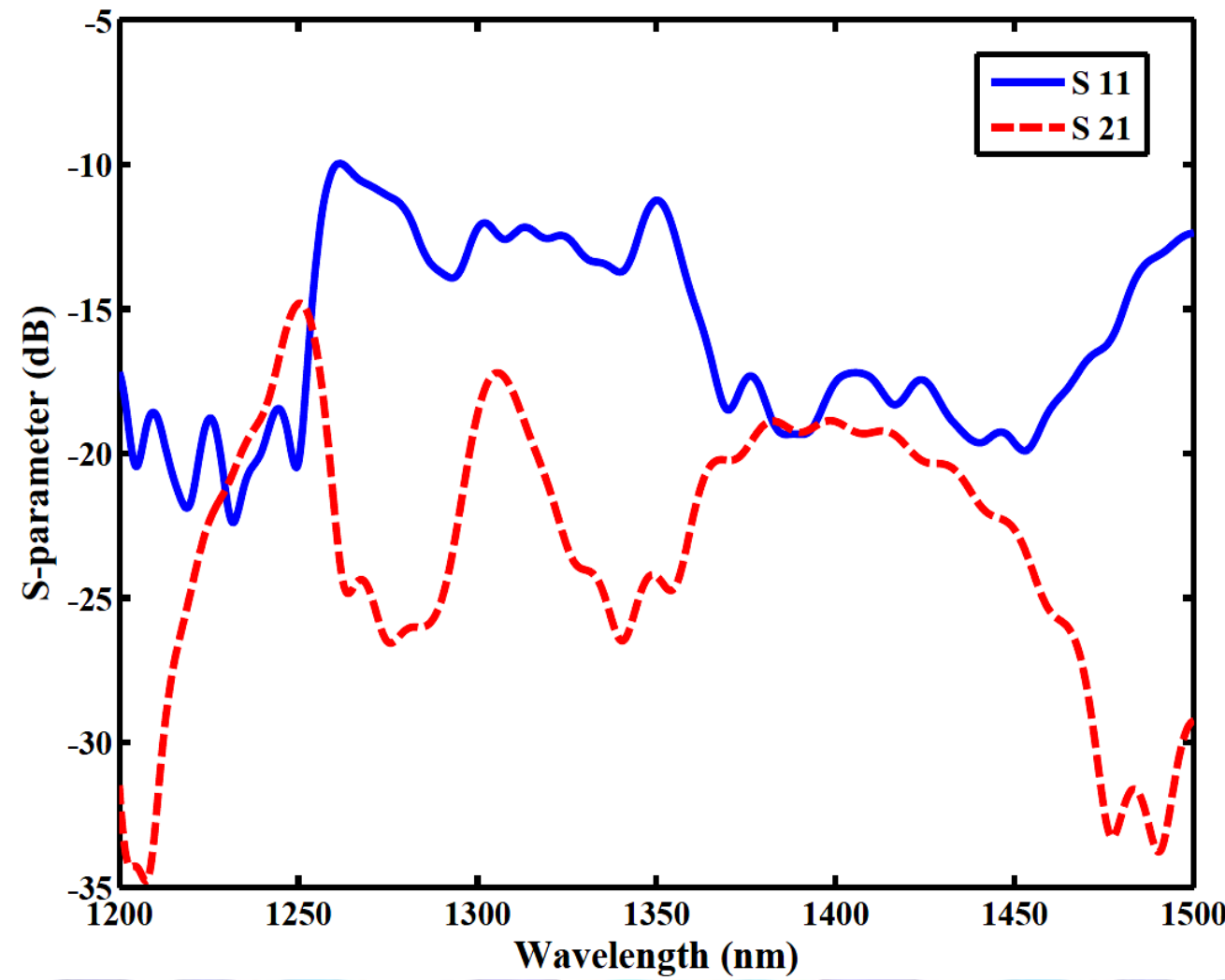

Fig. 2:Variation of scattering parameters $S_{11}$ and $S_{21}$ with wavelength for a 30 silicon-bar OLWA with grating period $830 \mathrm{~nm}$.

(a) 3D farfield pattern (b) yz plane (c) xy plane (d) xz plane.

$$
d=\frac{\lambda}{n_{e f f}-n_{b} \cos \theta}
$$

Figures 2 and 3 show the spectra of the scattering parameters $S_{11}$ and $S_{21}$ and the radiation patterns when the number of silicon perturbations $\mathrm{N}$ equals 30 , respectively, note that $S_{11}$ and $S_{21}$ are less than $-12 \mathrm{~dB}$ and $-17 \mathrm{~dB}$, respectively, for the $1300 \mathrm{~nm}$ wavelength. Results related to the $1550 \mathrm{~nm}$ LWA are listed in table 1 for comparison purposes. The values indicate clearly that the reflected and transmitted powers are almost negligible with radiated power. The direction of the main beam is $93^{\circ}$ which is in accord with the designed value $\left(\theta_{\text {shift }}=-2.5^{\circ}\right.$, i.e., main beam direction is $\left.92.5^{\circ}\right)$. Table 1 summarizes the main radiation parameters values at $1300 \mathrm{~nm}$ compared to these at $1550 \mathrm{~nm}$. 


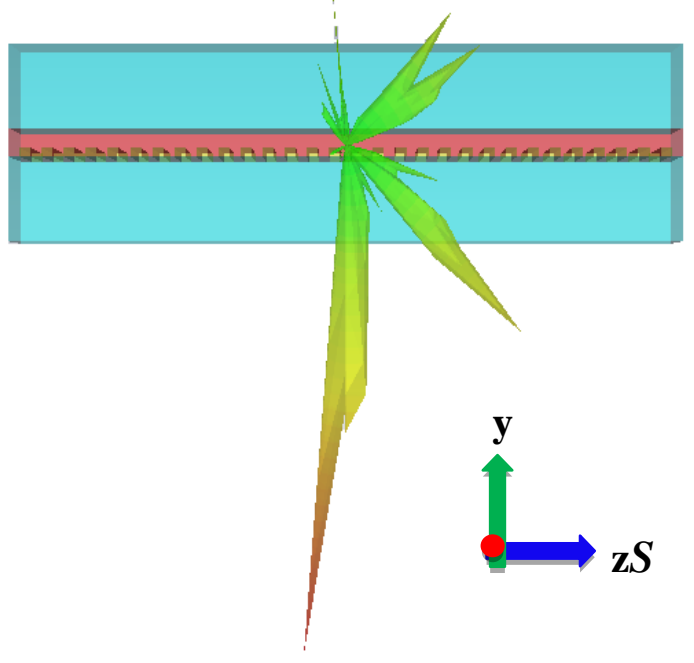

(a)

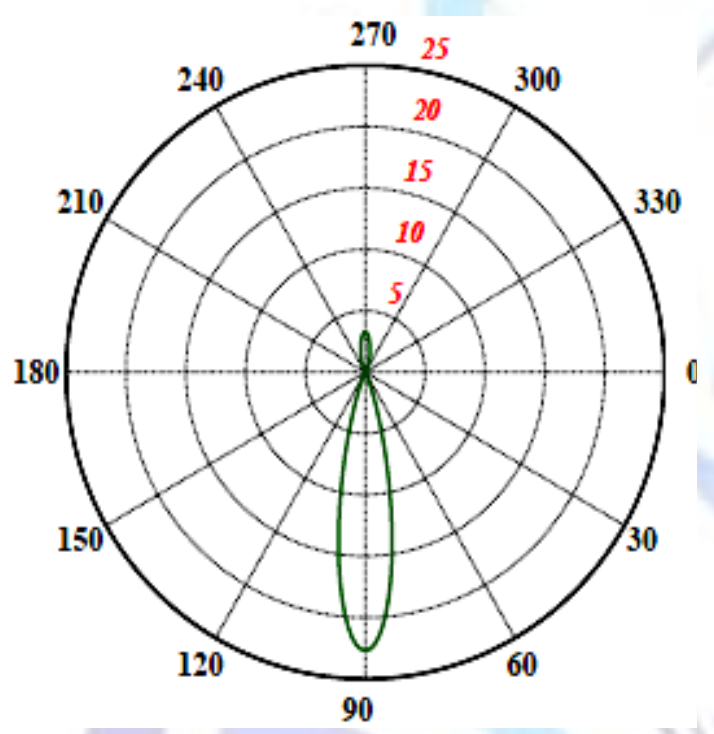

(c)

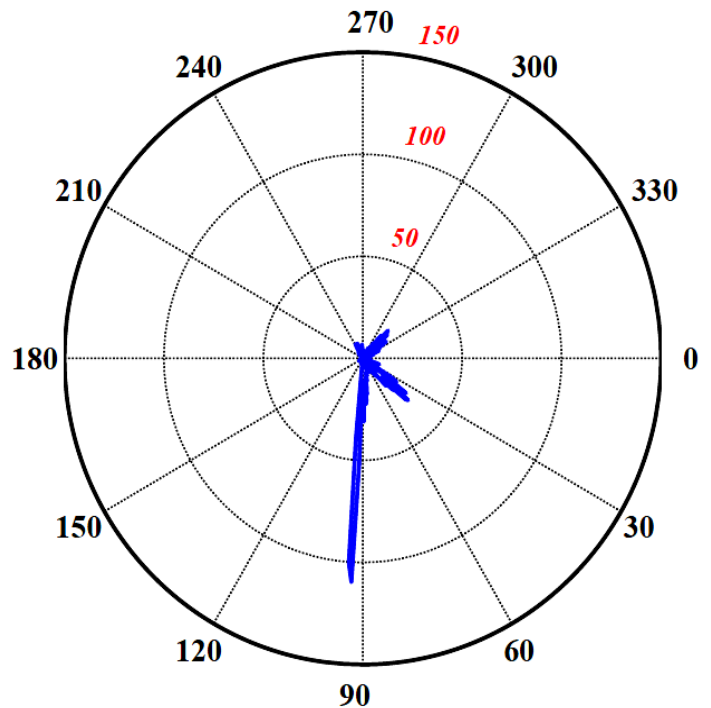

(b)

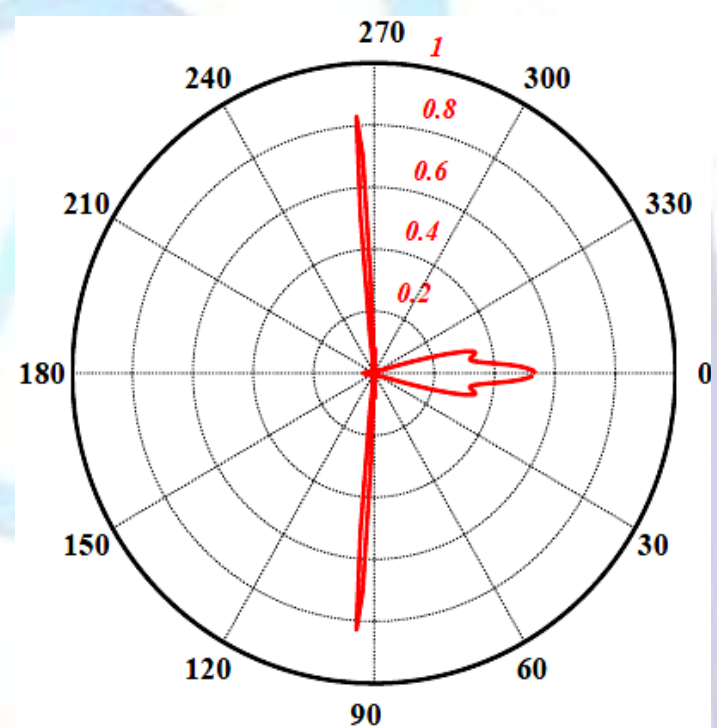

(d)

Fig. 3: Far-field characteristics of an OLWA operating at $1300 \mathrm{~nm}$. 


\begin{tabular}{|l|c|c|}
\hline \multirow{2}{*}{ Radiation parameter } & \multicolumn{2}{|c|}{ Value } \\
\cline { 2 - 3 } & $\mathbf{1 3 0 0} \mathbf{~ n m}$ antenna & $\mathbf{1 5 5 0} \mathbf{~ n m}$ antenna \\
\hline $\mathbf{S}_{\mathbf{1 1}}(\mathbf{d B})$ & -12.24 & -14.27 \\
\hline $\mathbf{S}_{\mathbf{2 1}}(\mathbf{d B})$ & -17.28 & -18.29 \\
\hline Radiation efficiency & 0.73 & 0.87 \\
\hline Total efficiency & 0.68 & 0.82 \\
\hline Directivity (dB) & 16.25 & 19.77 \\
\hline Gain (dB) & 11.88 & 39.36 \\
\hline Main lobe magnitude (dB) & 20.41 & 22.77 \\
\hline Main lobe direction (degree) & 93.00 & 93.00 \\
\hline Side lobe level (dB) & -5.50 & -9.30 \\
\hline 3 dB angular width (degree) & 2.60 & 3.00 \\
\hline
\end{tabular}

Table.1 Comparison of the values of radiation parameters between two OLWAs operating at wavelengths 1300 and $1550 \mathrm{~nm}$ with $\mathrm{N}=30$.

Investing the results in Table 1 highlights the following finding. The $1300 \mathrm{~nm}$ antenna has lower gain and efficiency compared with $1550 \mathrm{~nm}$ counterpart. The relatively lower efficiency result is attributed mainly to the higher losses of the waveguide at1300 $\mathrm{nm}$ as explained in the following.

The power incident on the antenna $P_{\text {in }}$ is splitted into reflected power at the input facet $P_{r}$, power transmitted from the output facet $P_{t}$, power absorbed by the waveguide $P_{\text {loss }}$, and radiated power $P_{\text {rad. }}$.

$$
\begin{array}{r}
P_{\text {in }}=P_{r}+P_{t}+P_{\text {rad }}+P_{\text {loss }} \\
\qquad 1=\frac{P_{r}}{P_{\text {in }}}+\frac{P_{t}}{P_{\text {in }}}+\frac{P_{\text {rad }}}{P_{\text {in }}}+\frac{P_{\text {loss }}}{P_{\text {in }}}
\end{array}
$$

Recall that $\mathrm{P}_{\mathrm{r}} / \mathrm{P}_{\text {in }}=S_{11}^{2}, \mathrm{P}_{\mathrm{t}} / \mathrm{P}_{\text {in }}=S_{21}^{2}$, and $\mathrm{P}_{\text {rad }} / \mathrm{P}_{\text {in }}=\eta_{\text {tot }}$, then

$P_{\text {loss }} / P_{\text {in }}=1-\left(S_{11}^{2}+S_{21}^{2}+\eta_{\text {tot }}\right)$

The radiation efficiency is calculated from

$$
\eta_{\text {rad }}=\frac{P_{\text {rad }}}{P_{\text {rad }}+P_{\text {loss }}}=\frac{P_{\text {rad }} / P_{\text {in }}}{P_{\text {rad }} / P_{\text {in }}+P_{\text {loss }} / P_{\text {in }}}=\frac{\eta_{\text {tot }}}{\eta_{\text {tot }}+P_{\text {loss }} / P_{\text {in }}}
$$

\section{Therefore}

$P_{\text {loss }} / P_{\text {in }}=\frac{\eta_{\text {tot }}}{\eta_{\text {rad }}}-\eta_{\text {tot }}$

For the $1300 \mathrm{~nm}$ antenna, $\mathrm{S}_{11}=-12.24 \mathrm{~dB}, \mathrm{~S}_{21}=-17.28 \mathrm{~dB}, \eta_{\mathrm{rad}}=0.73$, and $\eta_{\text {tot }}=0.68$. Therefore, $\mathrm{P}_{\mathrm{r}} / \mathrm{P}_{\text {in }}=0.06, \mathrm{P}_{\mathrm{t}} / \mathrm{P}_{\text {in }}=$ 0.0187 , and $P_{\text {loss }} / P_{\text {in }}=0.241$ (from eqn. 2) or 0.251 (from eqn. 3). Similar calculations are performed for the $1550 \mathrm{~nm}$ antenna which yield $\mathrm{P}_{\mathrm{r}} / \mathrm{P}_{\text {in }}=0.0374, \mathrm{P}_{\mathrm{t}} / \mathrm{P}_{\text {in }}=0.0148, \mathrm{P}_{\text {loss }} / \mathrm{P}_{\text {in }}=0.128$ (from eqn.. 2), and 0.123 (from eqn. 3). These results indicate clearly that the $1300 \mathrm{~nm}$ antenna has higher losses than the $1550 \mathrm{~nm}$ antenna (approximately twice) leading to lower total and radiation efficiencies. 
Table.1 Comparison of the values of radiation parameters between two OLWAs operating at wavelengths 1300 and $1550 \mathrm{~nm}$ with $\mathrm{N}=30$.

\begin{tabular}{|l|c|c|}
\hline \multirow{2}{*}{ Radiation parameter } & \multicolumn{2}{|c|}{ Value } \\
\cline { 2 - 3 } & $\mathbf{1 3 0 0} \mathbf{~ n m}$ antenna & $\mathbf{1 5 5 0} \mathbf{~ n m}$ antenna \\
\hline $\mathbf{S}_{\mathbf{1 1}}(\mathbf{d B})$ & -12.24 & -14.27 \\
\hline $\mathbf{S}_{\mathbf{2 1}}(\mathbf{d B})$ & -17.28 & -18.29 \\
\hline Radiation efficiency & 0.73 & 0.87 \\
\hline Total efficiency & 0.68 & 0.82 \\
\hline Directivity (dB) & 16.25 & 19.77 \\
\hline Gain (dB) & 11.88 & 39.36 \\
\hline Main lobe magnitude (dB) & 20.41 & 22.77 \\
\hline Main lobe direction (degree) & 93.00 & 93.00 \\
\hline Side lobe level (dB) & -5.50 & -9.30 \\
\hline 3 dB angular width (degree) & 2.60 & 3.00 \\
\hline
\end{tabular}

\section{3- Double-Grating Optical Leaky-Wave Antenna}

This section proposes new silicon-based LWA having two silicon perturbations layers (gratings) inserted in the $\mathrm{Si}_{3} \mathrm{~N}_{4}$ waveguide core. The effective core is bounded by the two gratings as shown in Fig. 4 . The Si perturbation width w and grating period $d$ are identical for both gratings and chosen to support the required operating wavelength. This leaves two parameters that can be used to tune the radiation characteristics of the two radiation beams. The first parameter is the thickness of the upper grating or/and lower grating while the other parameter is the axial shift between the two gratings (see Fig. 3b). The normalized axial shift (NAS) is defined as $\Delta z / w$ where $\Delta z$ represents the axial offset between the two gratings. Therefore, $w-\Delta z$ represents the axial overlapping between the upper and lower silicon perturbation elements. For $\mathrm{NAS}=0$, the upper grating is axially identical to the lower grating. (i.e., the two gratings are in phase). For NAS=100\%, the two gratings are out of phase.

$\mathrm{SiO}_{2}$

Si bar

Si bar

$\mathrm{SiO}_{2}$

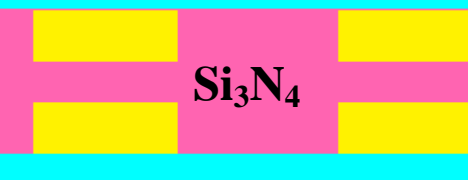

\section{$\mathrm{SiO}_{2}$}

(a)

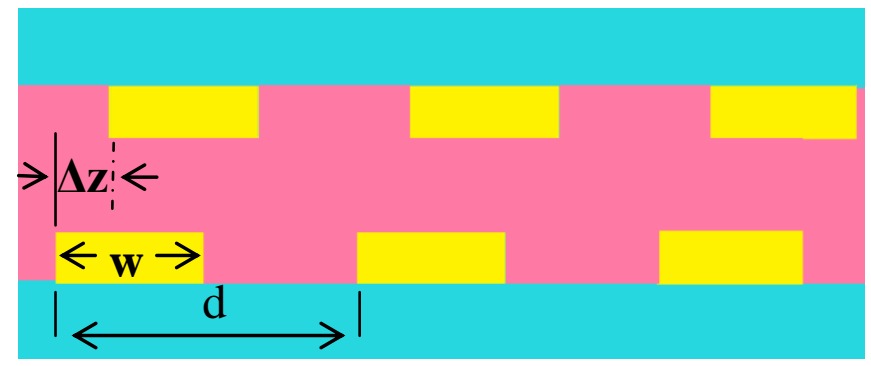

(b)

Fig. 4: (a) Schematic diagram of a double-grating leaky-wave antenna.

(b) Definition of the normalized axial shift parameter. 
The simulation results presented in this section are for $1550 \mathrm{~nm}$ double-grating antenna (DGA) designed with 30 silicon perturbations per grating (i.e., $\mathrm{N}=30$ ). Unless otherwise stated, the parameters values are $h_{w}=1000 \mathrm{~nm}, d=967.5 \mathrm{~nm}$, $\mathrm{w} / \mathrm{d}=0.5$, and $\mathrm{h}=300 \mathrm{~nm}$ (for both gratings).

\subsection{Performance of DGA Designed with NAS=0}

This structure can be considered as a conventional double-grating LWA introduced to yield two radiated main beams having identical radiation parameters. Figure 5 shows the spectra of the scattering parameters $S_{11}$ and $S_{21}$ when the antenna is designed with $\mathrm{N}=30$. The related radiation patterns are displayed in Fig. 6 . The main radiation parameters evaluated at $1550 \mathrm{~nm}$ are listed in Table 2. Results corresponding to a single-grating counterpart are also included in this table for comparison purposes. Investing these results highlights the following facts

(i) The DGA radiates two main beams having identical radiation characteristics. The direction angels of the main beams are $122^{\circ}$ and $238^{\circ}$.

(ii) The 2D radiation patterns in different planes can be spitted into two identical (symmetric) radiation patterns.

(iii) The radiation characteristics of the DGA is not the superposition (i.e., linear contribution) of two isolated SGAs. In fact the coupling between the two gratings cannot be neglected since the distance between them (400 $\mathrm{nm})$ is the operating wavelength (1550 nm).

(iv) The DGA has higher reflection coefficient (i.e., $S_{11}$ ) at the input (feeding) fact of the waveguide compared to the SGA. This result is attributed to the increase of refractive index of the core region since two silicon perturbations are inserted in transversal direction (normal to the direction of propagation).

(v) The DGA has slightly higher radiation efficiency and lower total efficiency compared with SGA.

(vi) The gain of the DGA is less by $27.7 \mathrm{~dB}$ compared with the gain of the SGA.

Note that the DGA has $S_{11}=-7.55 \mathrm{~dB}, S_{21}=-27.30 \mathrm{~dB}, \eta_{\text {tot }}=0.75$ at $1550 \mathrm{~nm}$. These values yield $P_{r} / P_{\text {in }}=0.1758, P_{t} / P_{\text {in }}=$ 0.0019 , and $P_{\text {loss }} / P_{\text {in }}=0.0723$ (from eqn. 5.2). Note also that the $D G A$ is characterized by higher $P_{r} / P_{\text {in }}$ and lower $P_{\text {loss }} / P_{\text {in }}$ compared with the SGA. These results lead to higher radiation efficiency and lower total efficiency for the DGA according to eqn.s. 1 and 2.

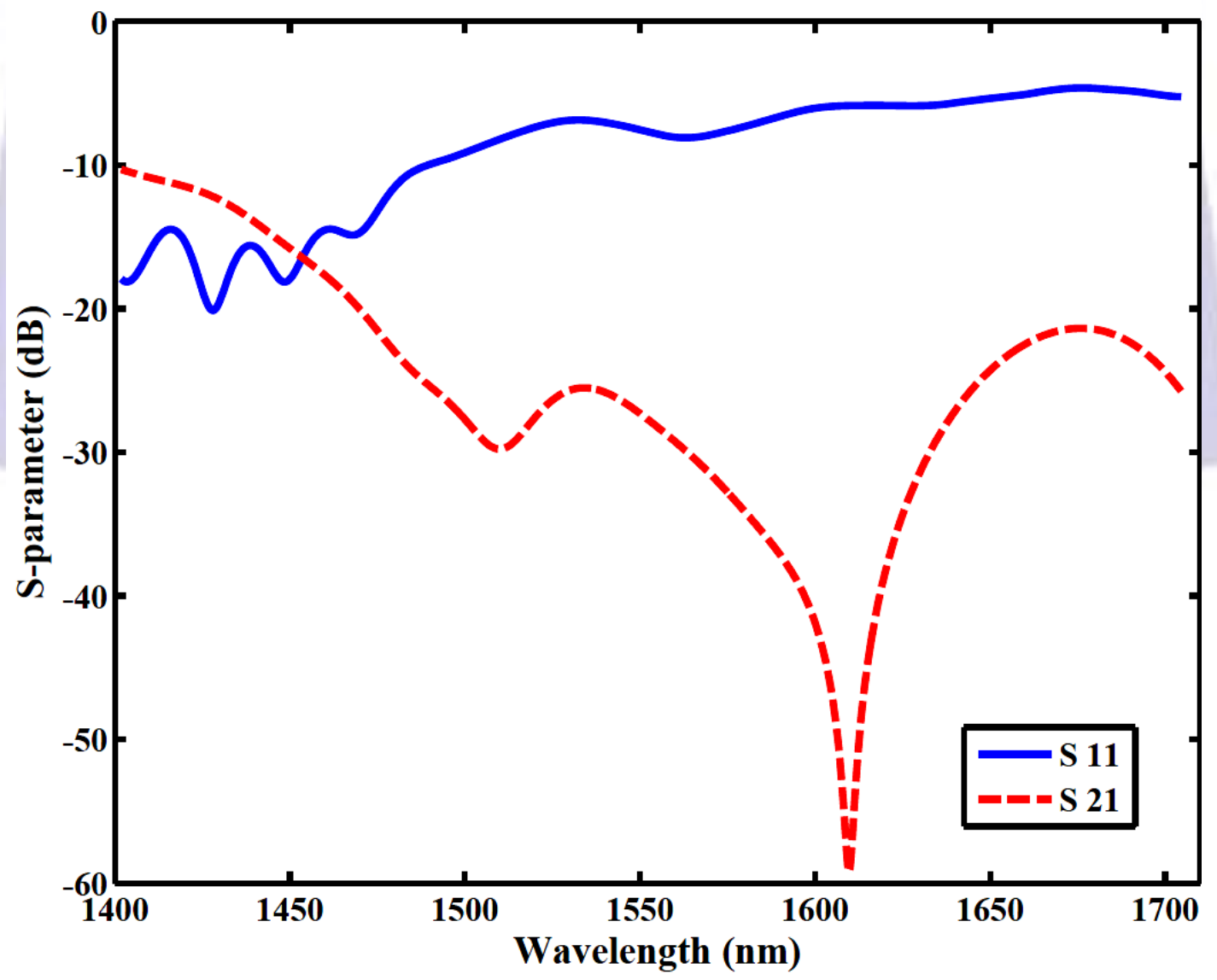

Fig. 5: Variation of scattering parameters $S_{11}$ and $S_{21}$ with wavelength for a 30 -silicon bar OLWA designed with double grating. 


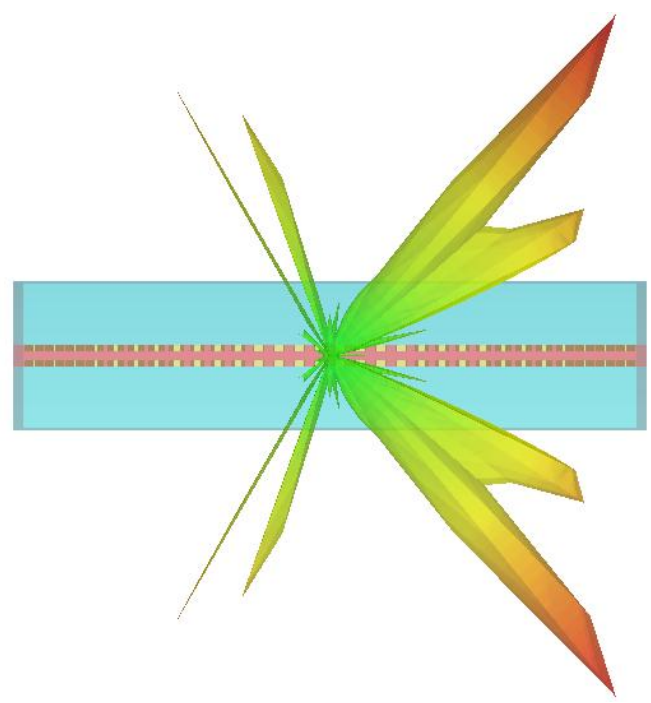

(a)

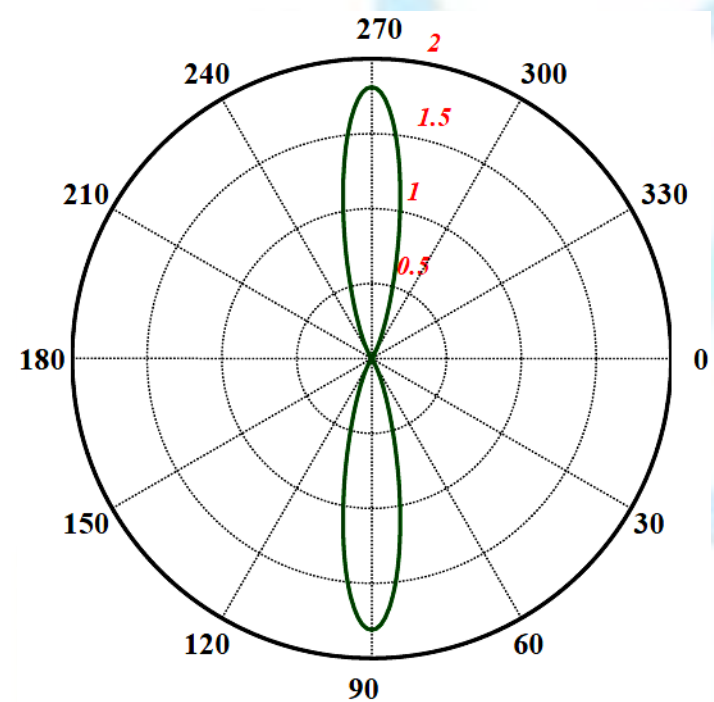

(c)

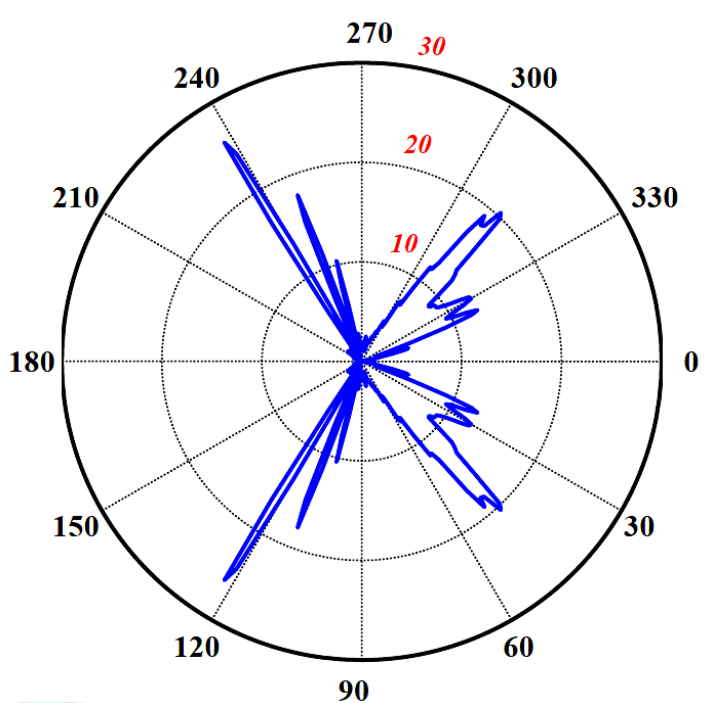

(b)

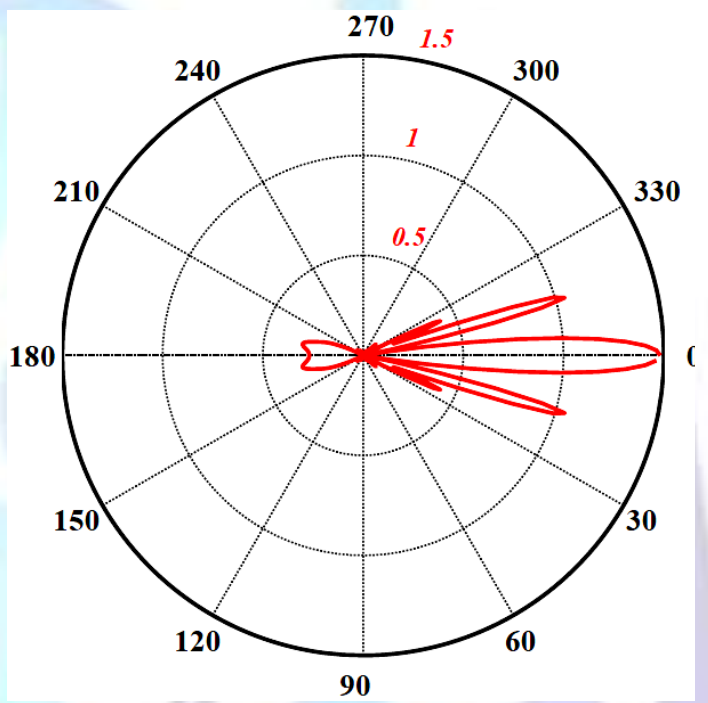

(d)

Fig. 6: Farfield characteristics of a double-grating OLWA designed with $\mathrm{N}=30$ and operating at $1550 \mathrm{~nm}$.

(a) 3D farfield pattern (b) yz plane (c) xy plane (d) xz plane. 
Table 2 Comparison between radiation parameters of DGA and SGA designed with $\mathrm{N}=30$ and operating at $1550 \mathrm{~nm}$.

\begin{tabular}{|l|c|c|}
\hline \multirow{2}{*}{ Radiation parameter } & \multicolumn{2}{c|}{ Value } \\
\cline { 2 - 3 } & DGA & SGA \\
\hline S11 (dB) & -7.55 & -14.27 \\
\hline S21 (dB) & -27.30 & -18.29 \\
\hline Radiation efficiency & 0.91 & 0.87 \\
\hline Total efficiency & 0.75 & 0.82 \\
\hline Directivity (dB) & 12.82 & 19.77 \\
\hline Gain (dB) & 11.66 & 39.36 \\
\hline Main lobe magnitude (dB) & 14.13 & 22.77 \\
\hline Main lobe direction (degree) & $122.00,238.00$ & 93.00 \\
\hline Side lobe level (dB) & -1.00 & -9.30 \\
\hline 3 dB angular width (degree) & 3.30 & 3.00 \\
\hline
\end{tabular}

\subsection{Effect of Axial Shift Between the Upper and Lower Grating}

The aim of this subsection is to address the effect of the axial shift between the two gratings on the radiation parameters of the DGA. The simulation results are presented here when the antenna is operated at $1550 \mathrm{~nm}$.

Figure 7 displays the radiation patterns for different values of NAS. The case of NAS zero corresponds to the conventional DGA investigated in Section 3.1. The variation of the radiation parameters evaluated at $1550 \mathrm{~nm}$ with the axial shift plotted in Fig. 8.

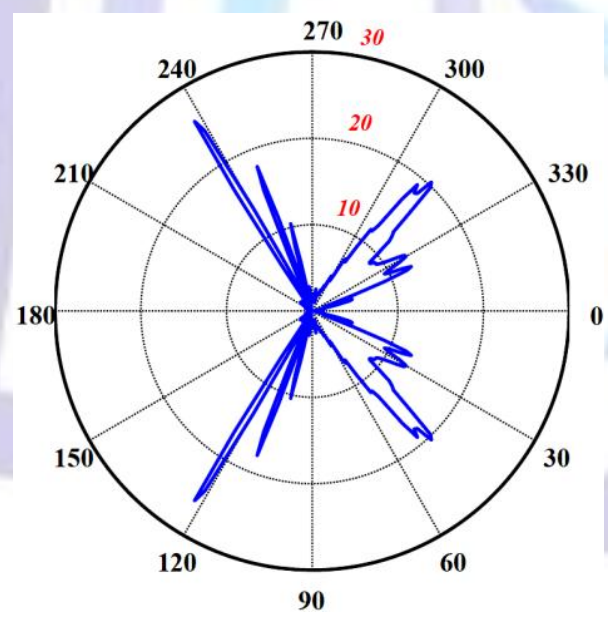

(a)

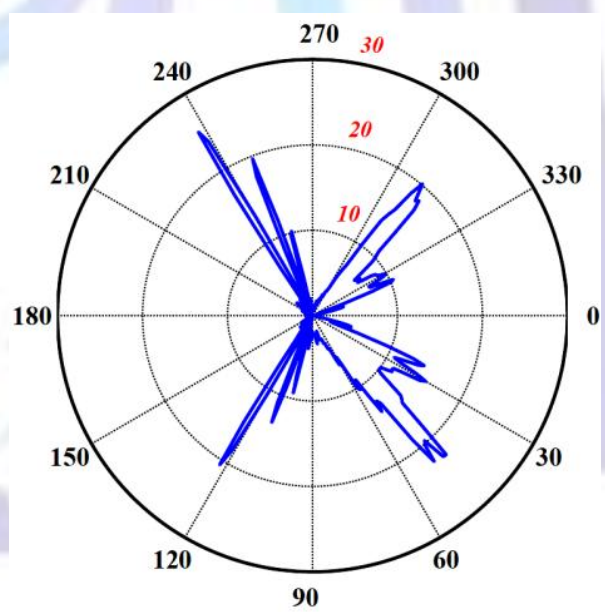

(b)

Fig. 7:Radiation patterns of a double-grating LWA designed with different values of NAS. The results are reported for $\mathrm{N}=30$ and $\lambda=1550 \mathrm{~nm}$. (a) 0 (b) 0.2 (c) 0.4 (d) 0.5 (e) 0.65 (f) 0.8 (g) 1 . 


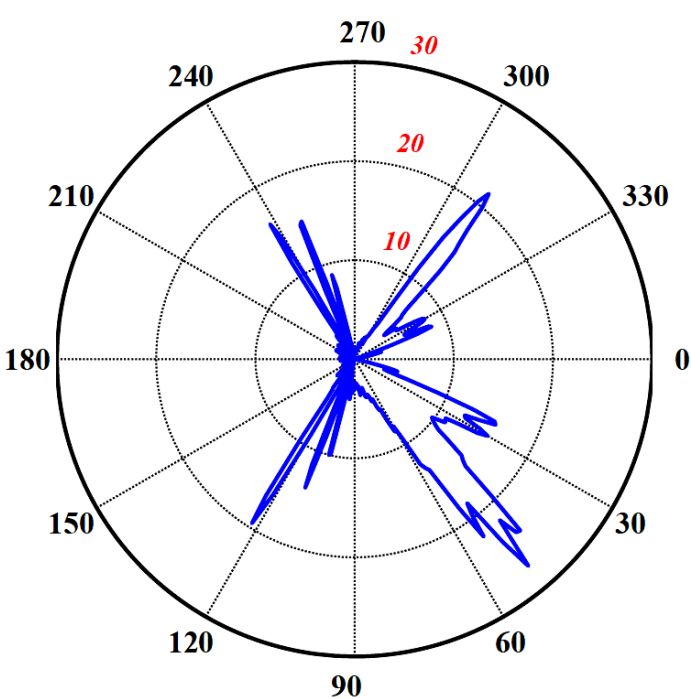

(c)

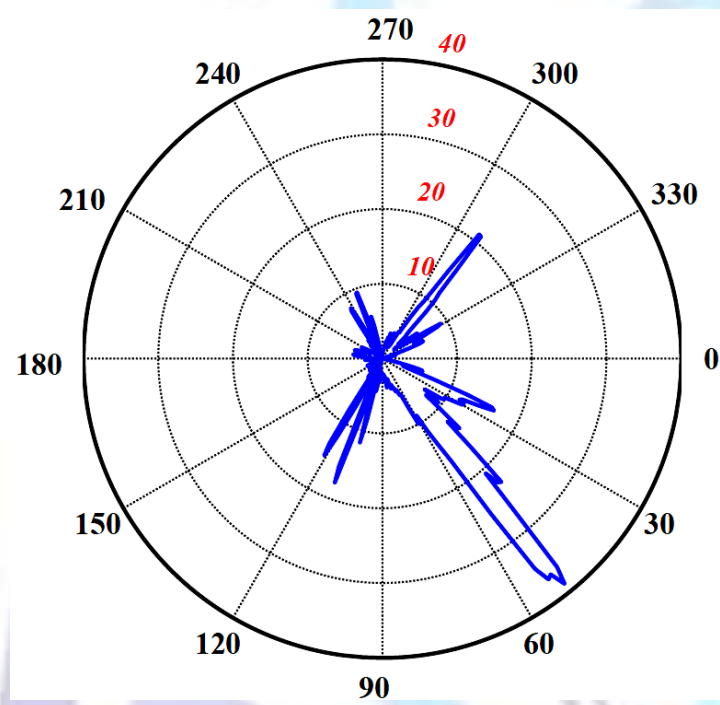

(e)

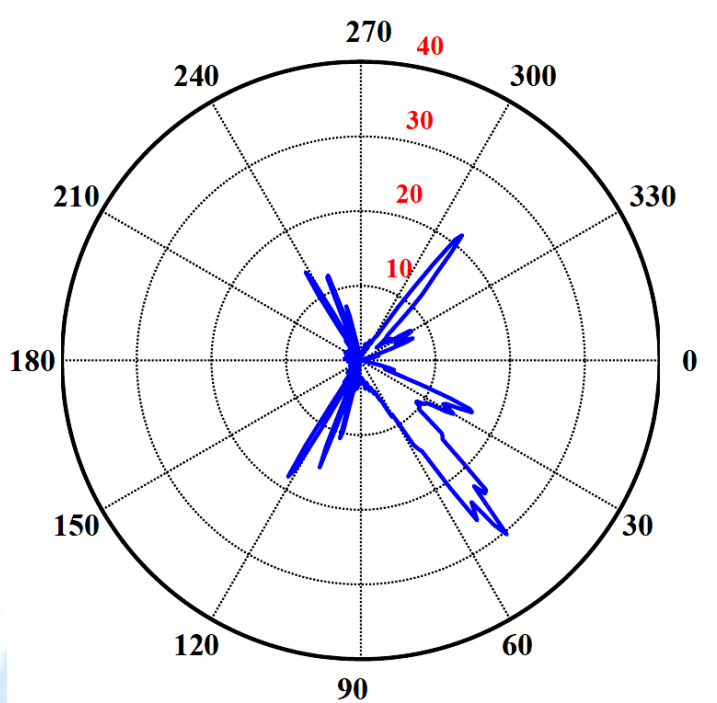

(d)

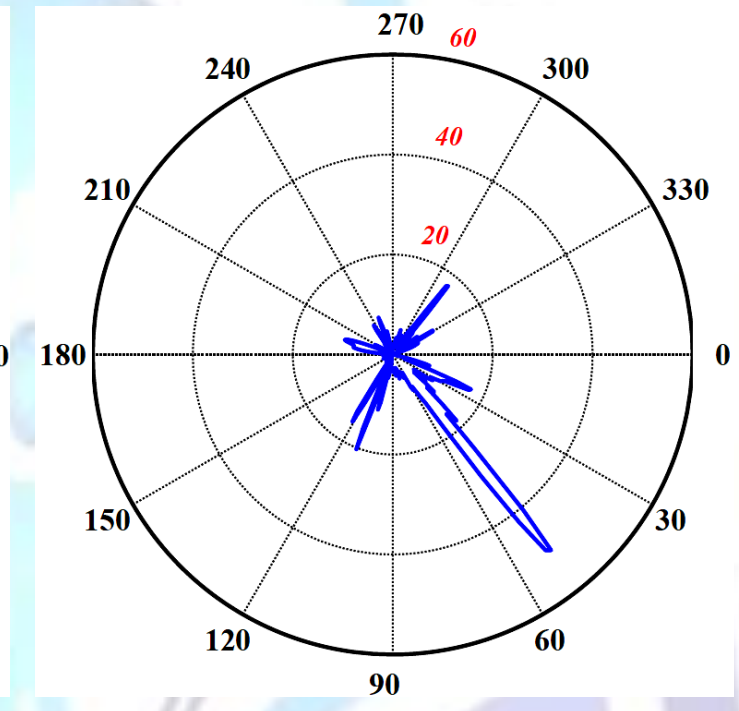

(f)

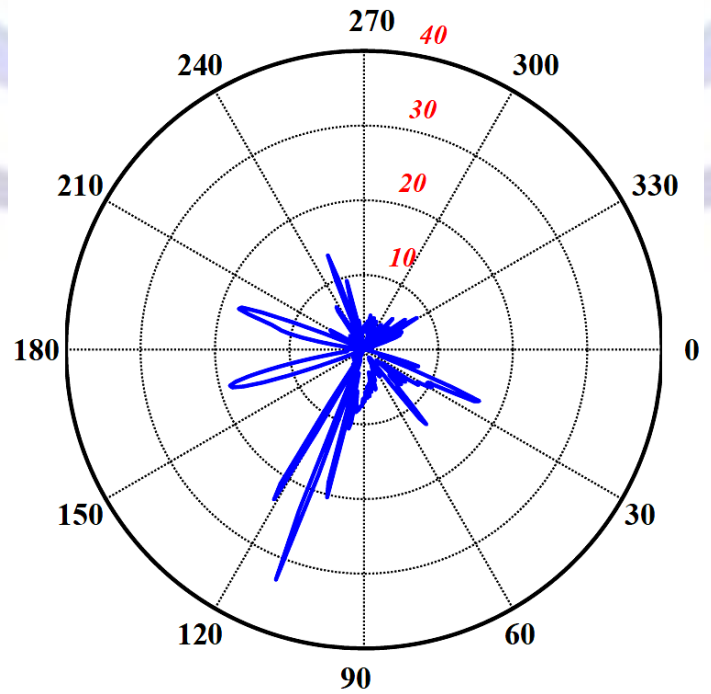

(g)

Fig. 7: (Continued). 


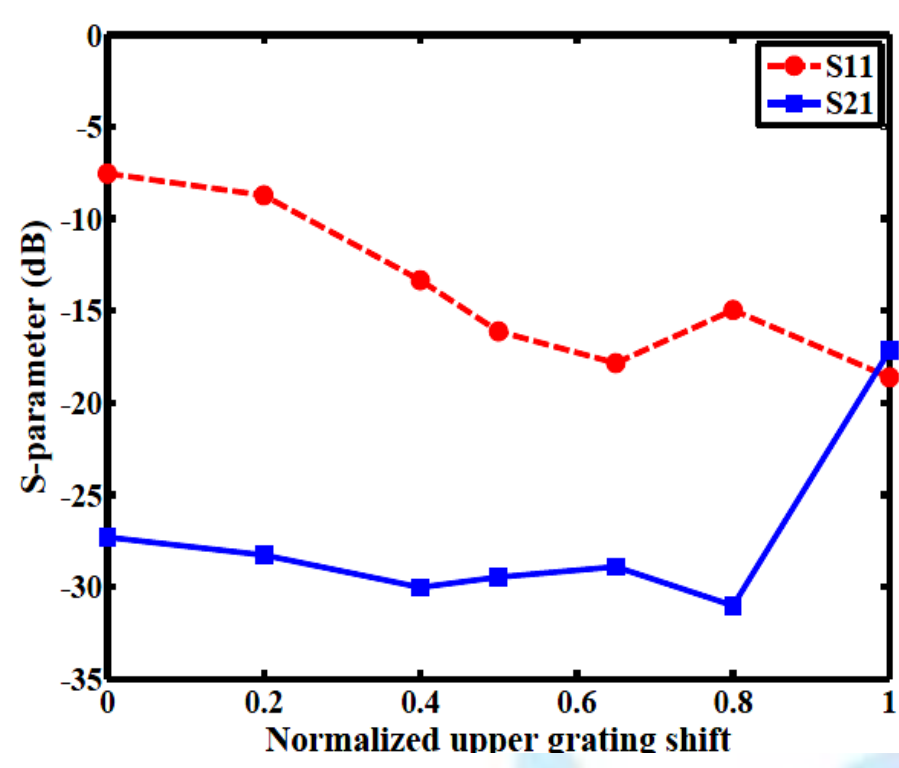

(a)

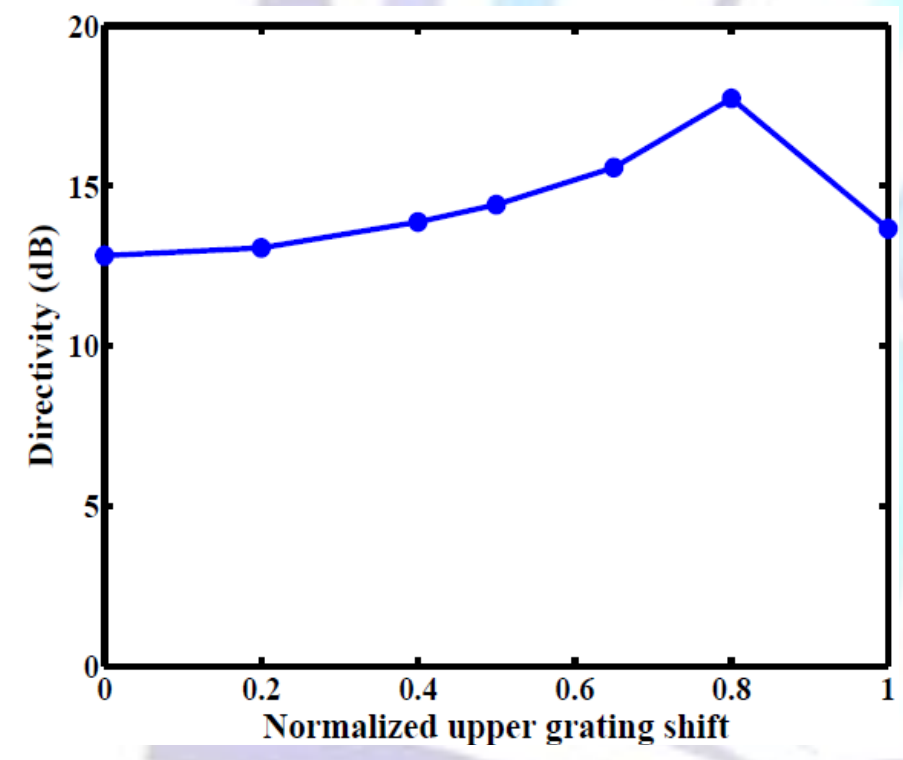

(c)

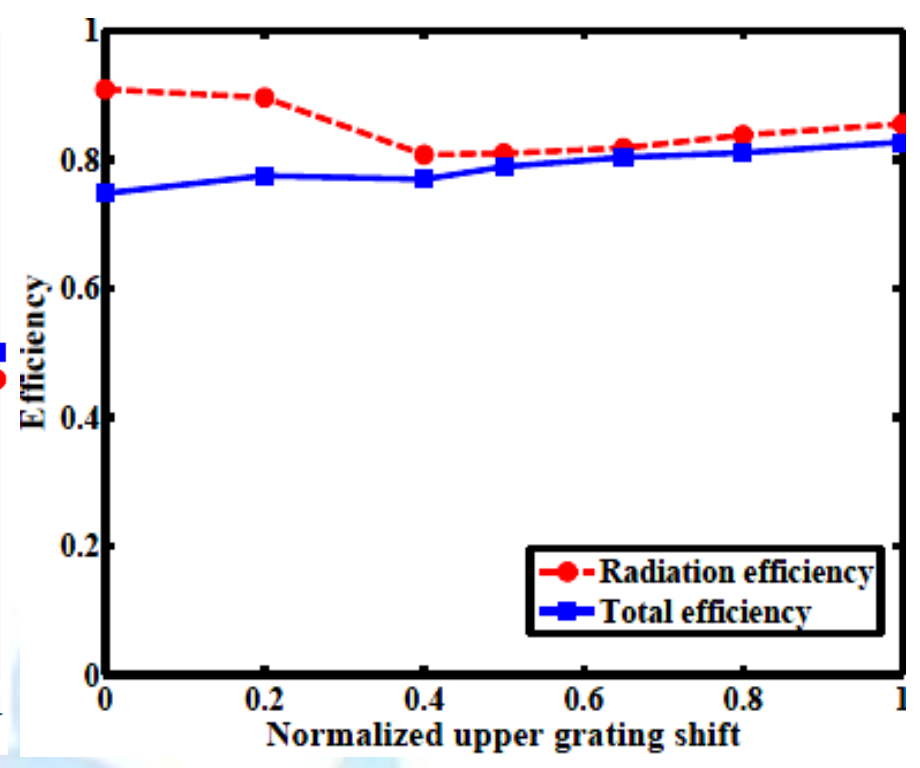

(b)

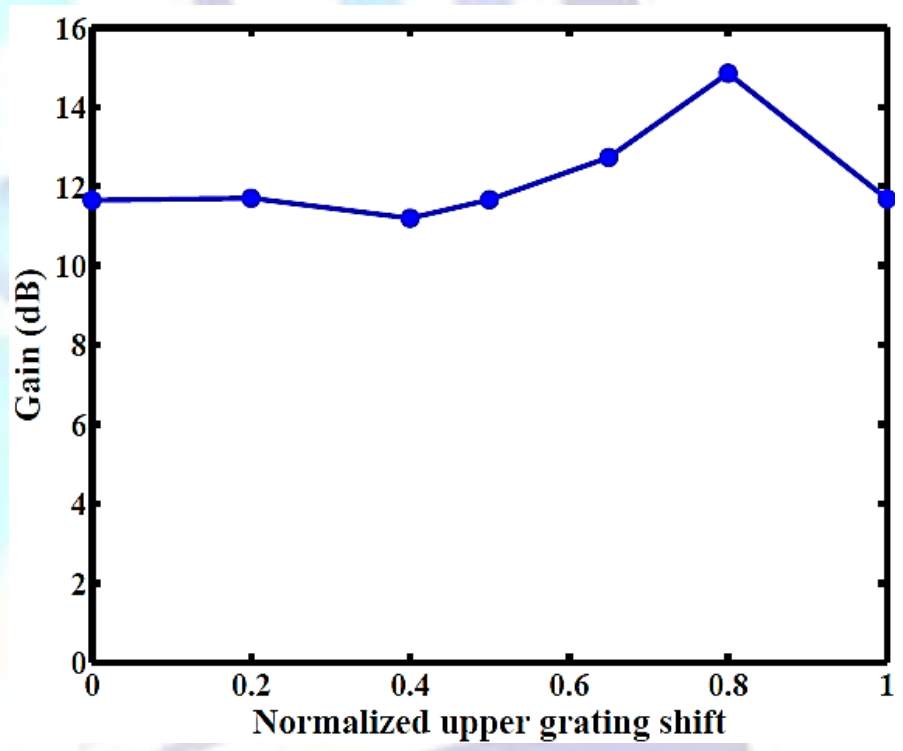

(d)

Fig. 8: Dependence of radiation parameters of a double-grating LWA on axial shift when $N=30$ and $\lambda=1550$ $\mathrm{nm}$.

(a) S-parameters (b) efficiency (c) directivity (d) gain (e) main lobe magnitude (f) main lobe direction (g) side lobe level (h) $3 \mathrm{~dB}$ angular width. 


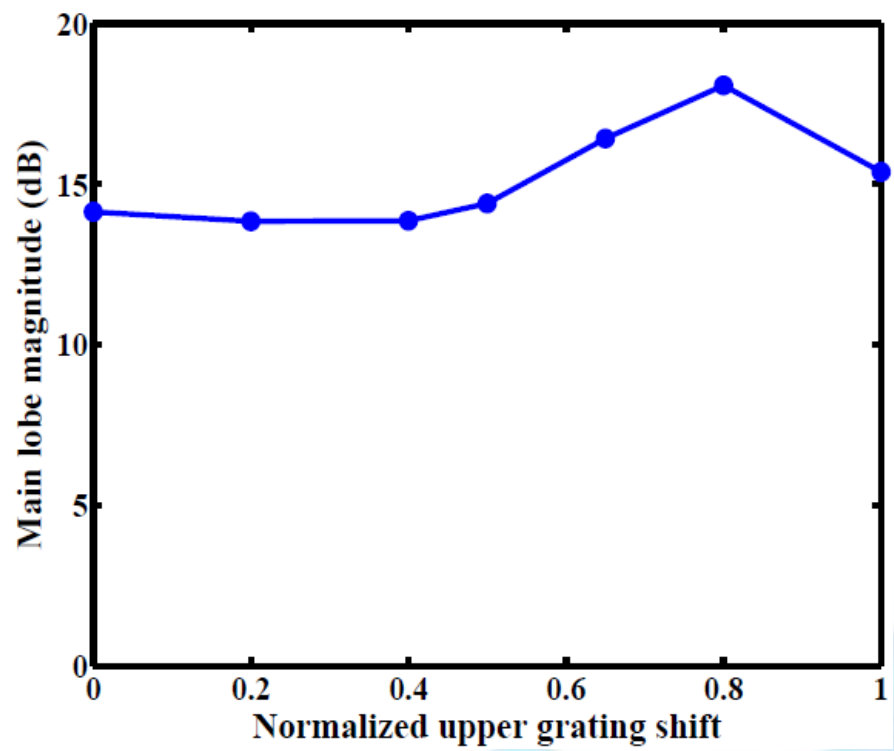

(e)

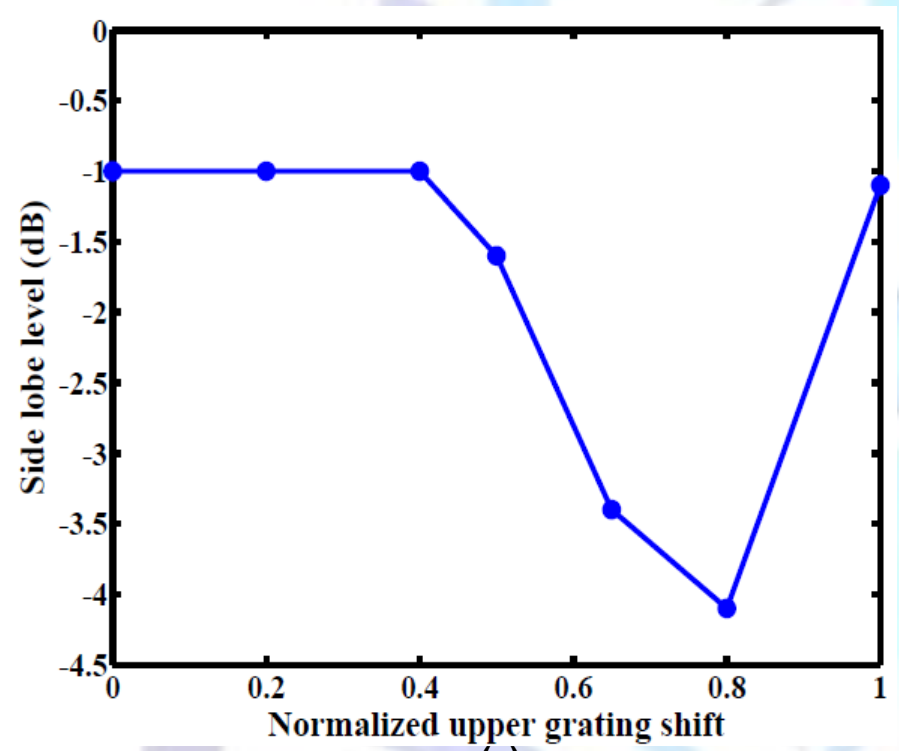

(g)

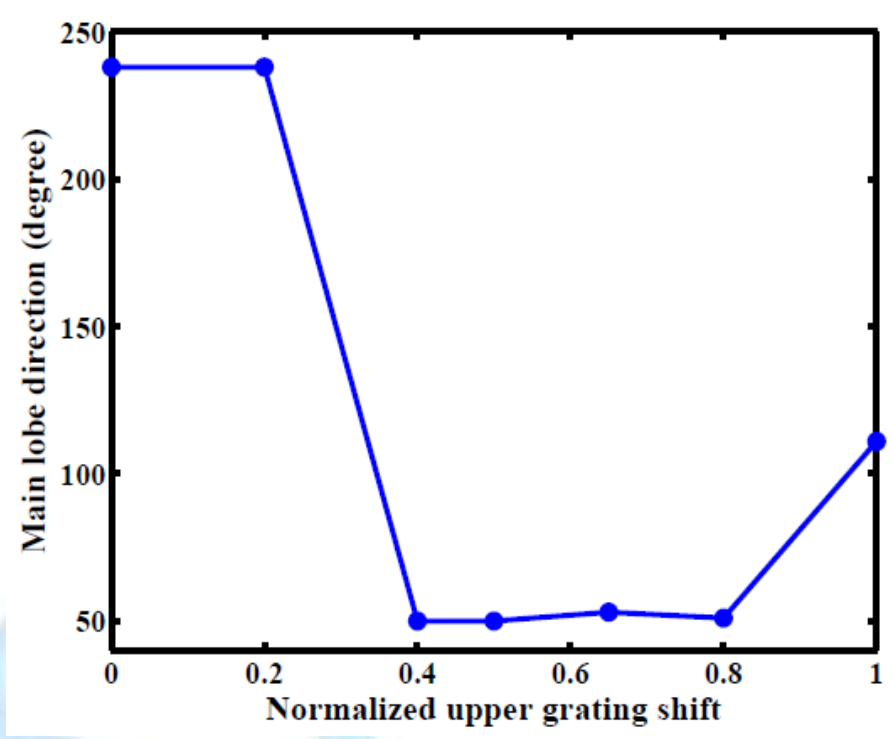

(f)

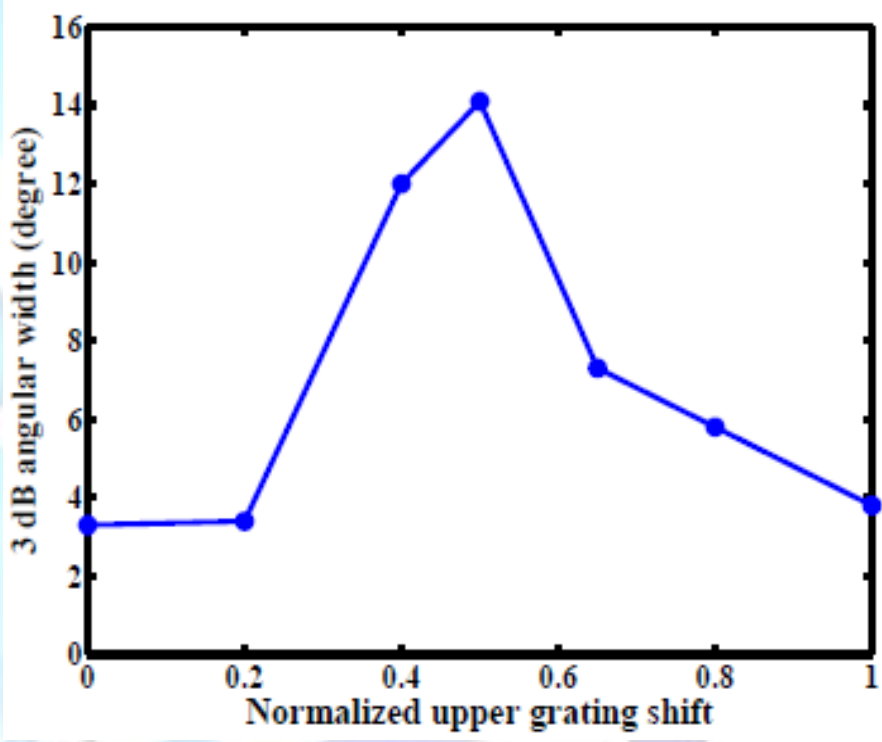

(h)

Fig. 8: (Continued).

\subsection{Effect of Upper Grating Thickness}

The radiation parameters of the DGA can be tuned by varying the thickness of the upper grating $\mathrm{h}_{\mathrm{u}}$. This point will be presented in this subsection by addressing the dependence of antenna characteristics on $h_{\mathrm{u}}$ while keeping the thickness of the lower grating fixed at $300 \mathrm{~nm}$. The NAS is set to zero in the following simulation. The case of $h_{u}=0$ corresponds to a single-grating LWA while the case of $h_{u}=300 \mathrm{~nm}$ corresponds to the conventional double-grating LWA. The values of the radiation pattern are estimated at $1550 \mathrm{~nm}$.

Figure 9 shows how the radiation pattern is affected by varying the thickness of the upper grating. Figure 10 shows the dependence of radiation parameters on the thickness of the upper grating. Note that the main beam direction varies over a wide range with the variation of the upper grating thickness. 


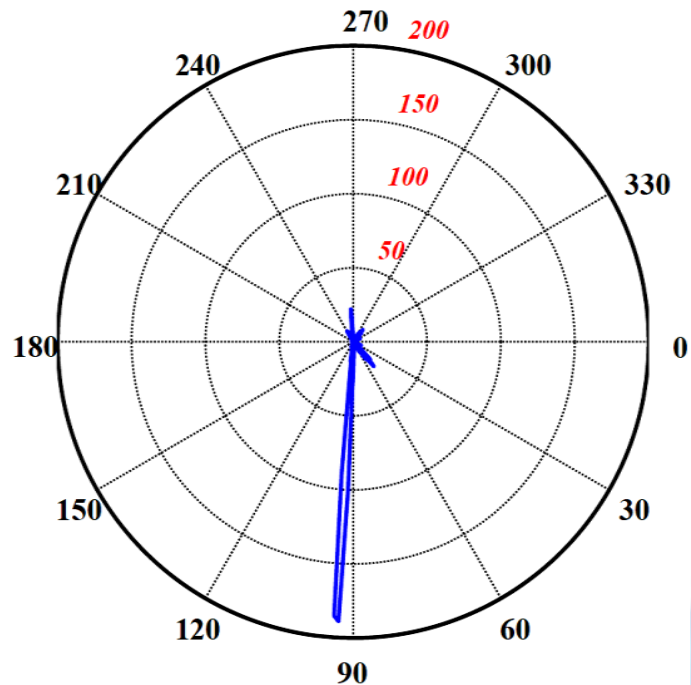

(a)

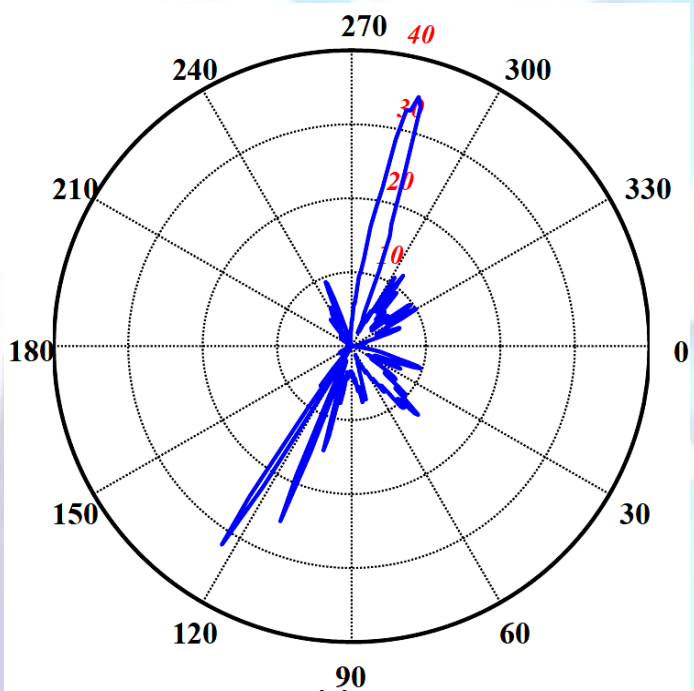

(c)

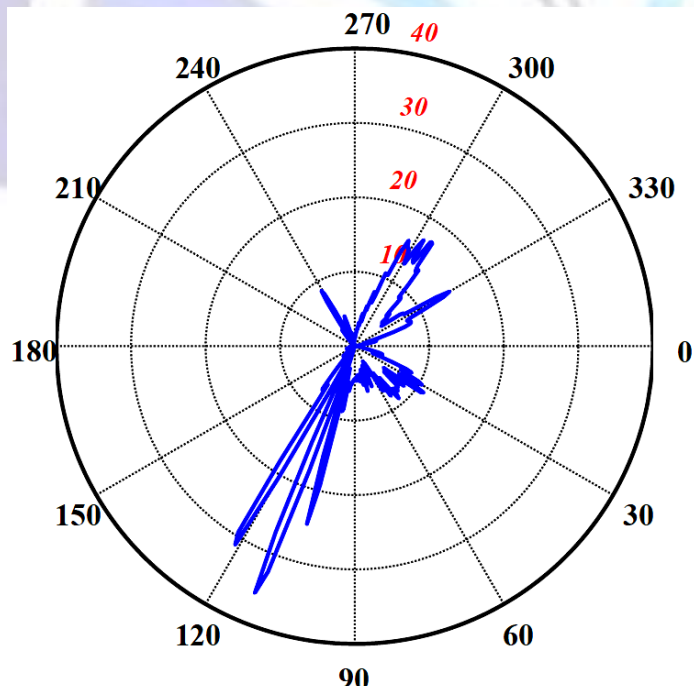

(e)

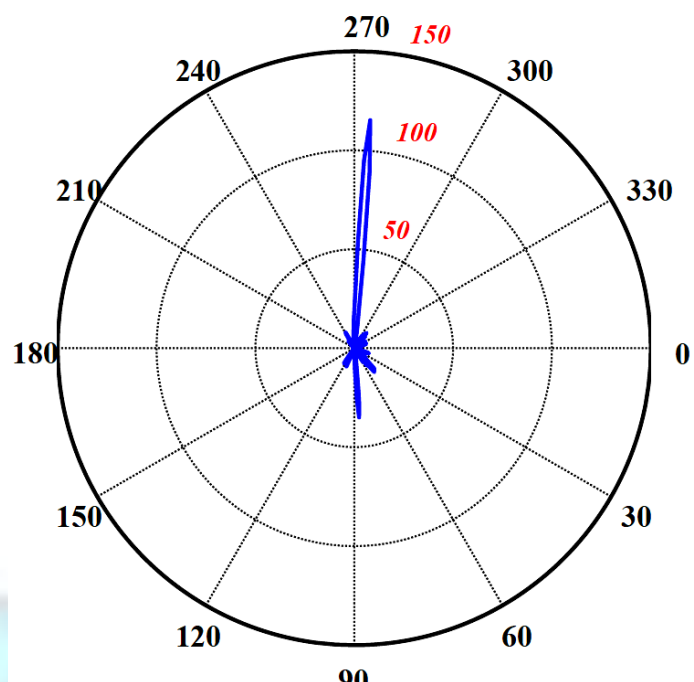

(b)

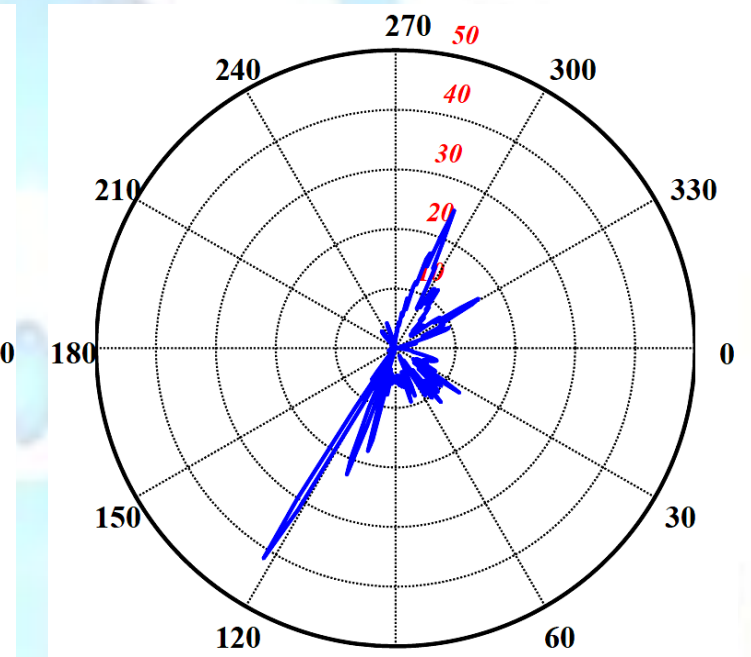

(d)

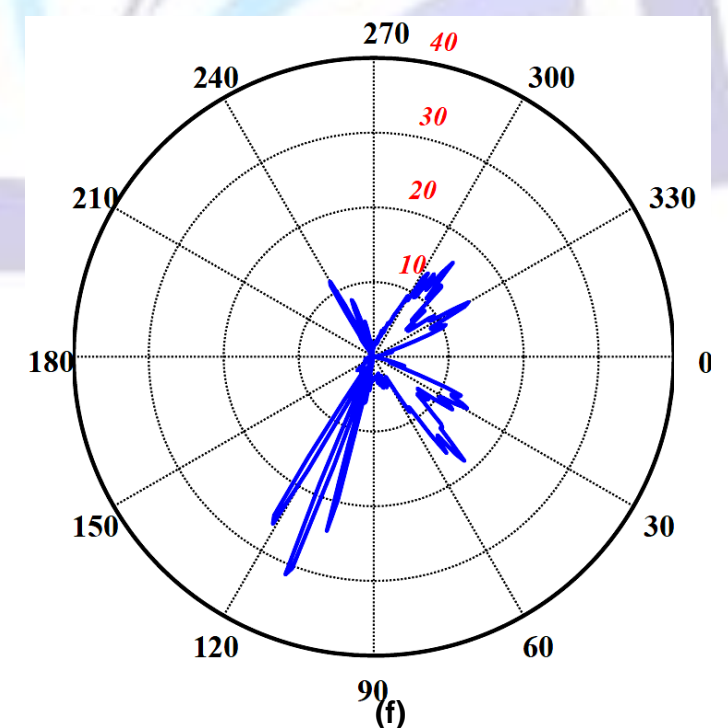

90 $\mathrm{f}$ )

Fig. 9:Radiation patterns of DGA designed different values of upper grating thickness. (a) $0 \mathrm{~nm}$ (b) $50 \mathrm{~nm}$ (c) $100 \mathrm{~nm}$ (d) $150 \mathrm{~nm}$ (e) $200 \mathrm{~nm}$ 


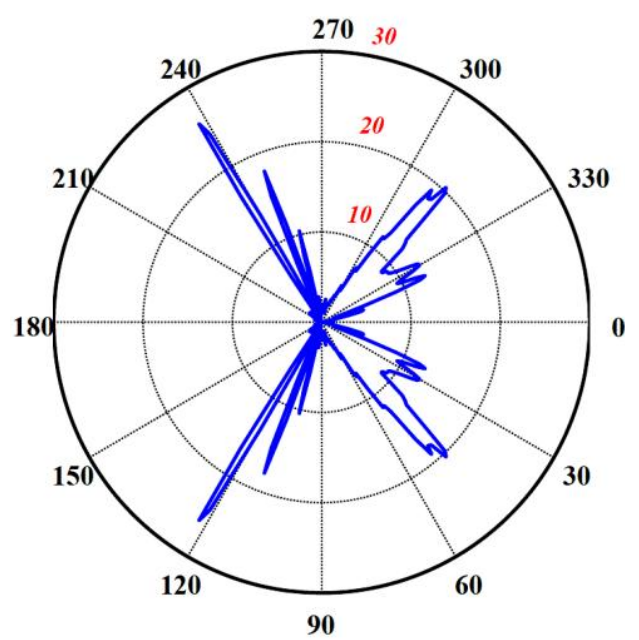

ISSN 2277-3061

(g)

Fig. 9:(Continued).

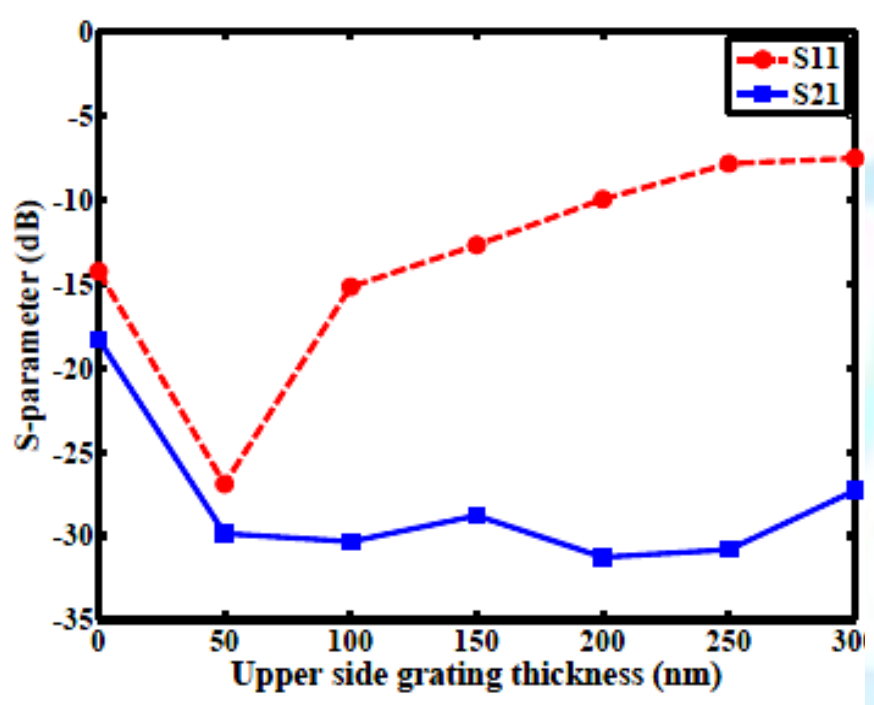

(a)

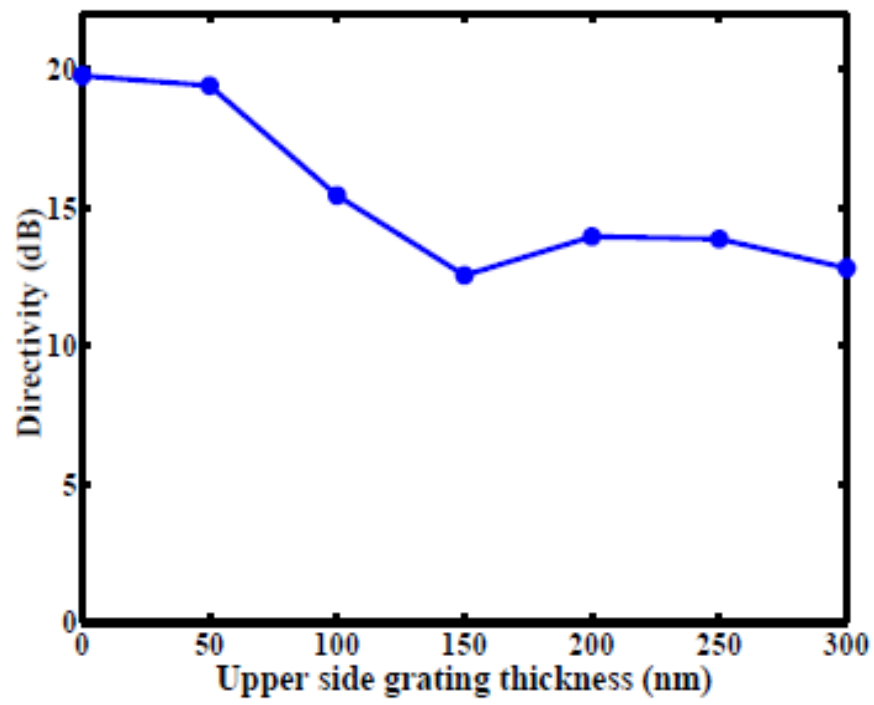

(c)

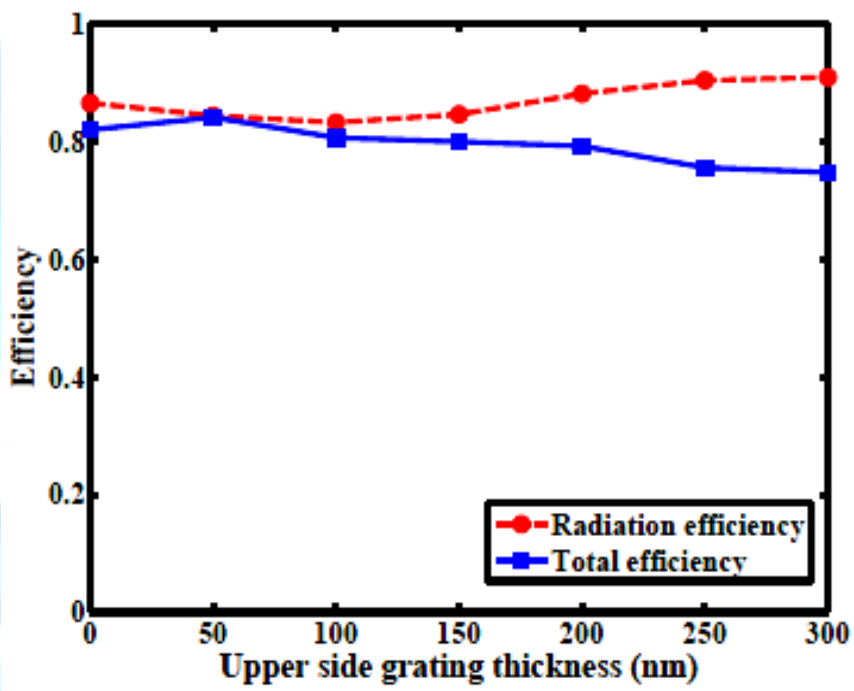

(b)

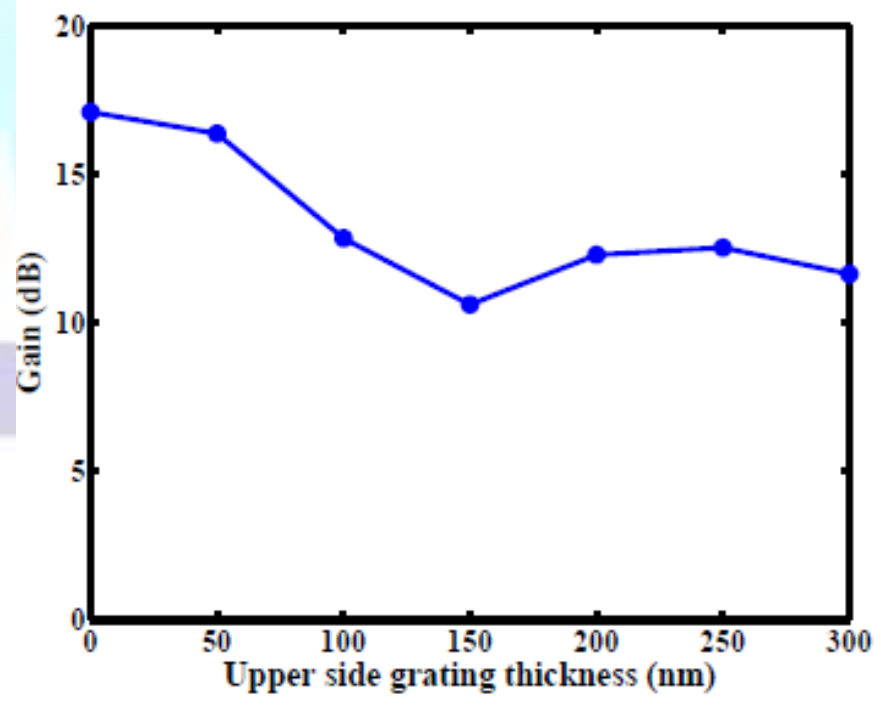

(d)

Fig. 10: variation of radiation parameters of a double-grating LWA with upper grating thickness when $N=30$ and $\lambda=1550 \mathrm{~nm}$. (a) S-parameters (b) efficiency (c) directivity (d) gain (e) main lobe magnitude (f) main lobe direction (g) side lobe level (h) $3 \mathrm{~dB}$ angular width. 


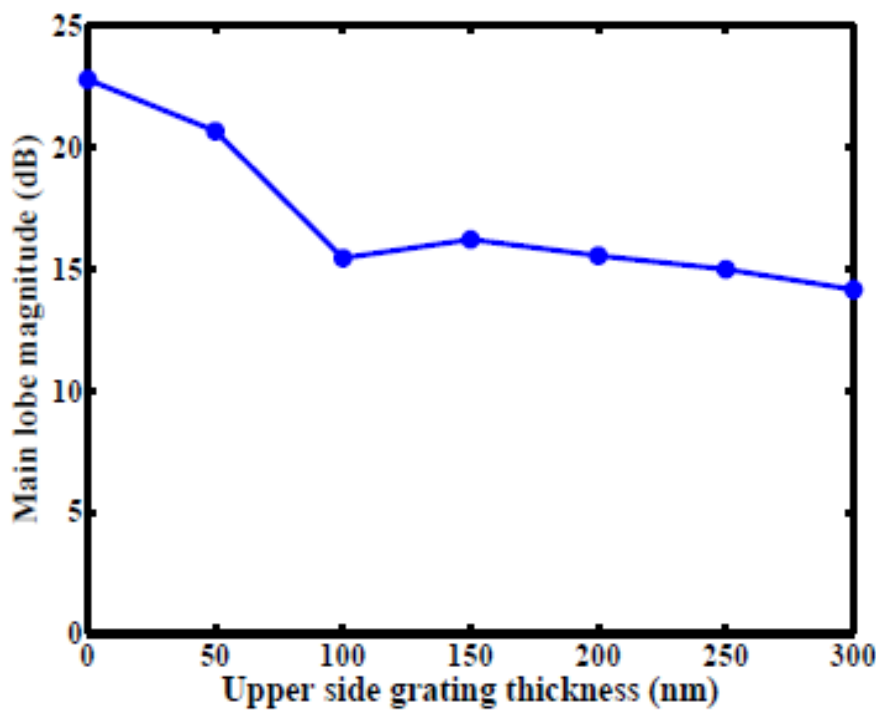

(e)

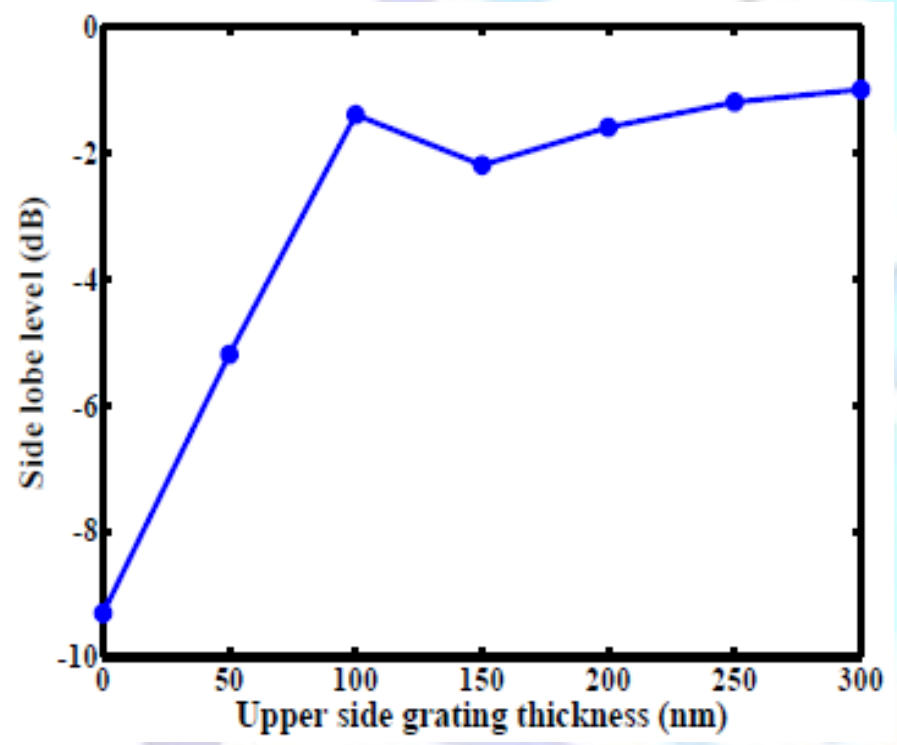

(g)

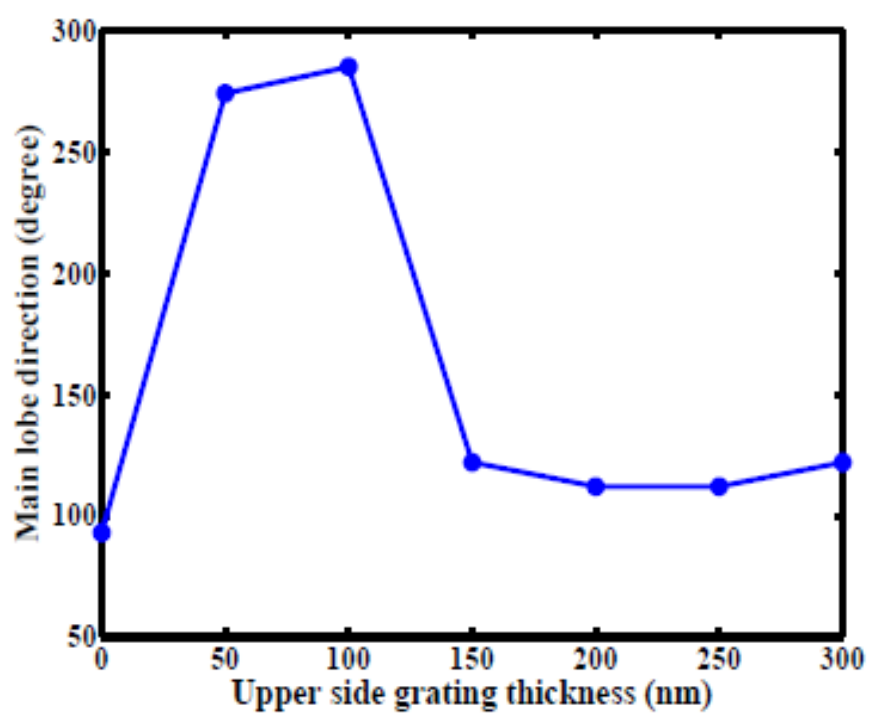

(f)

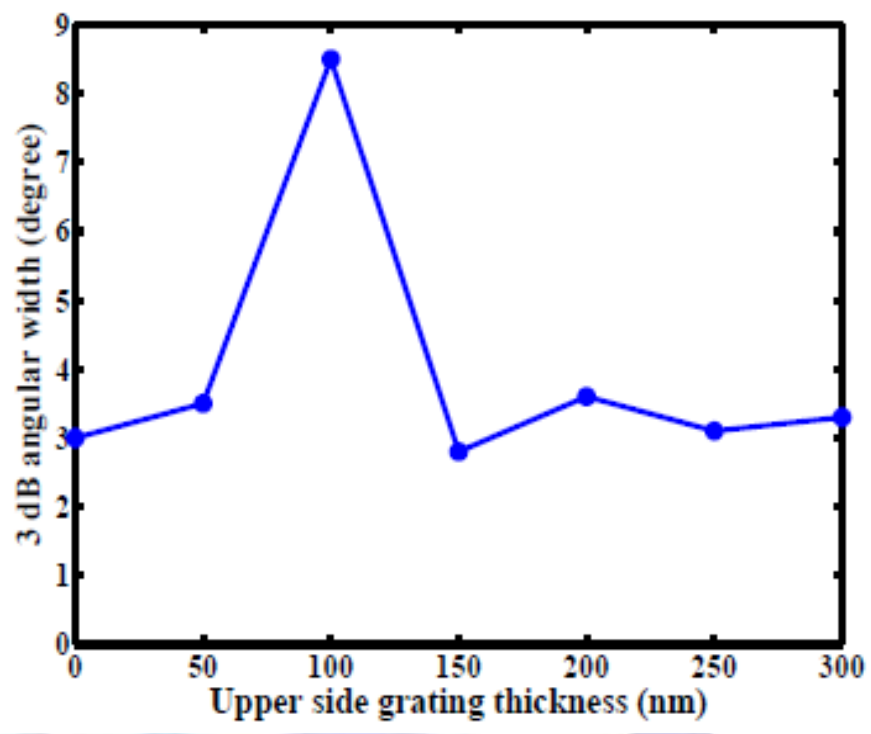

(h)

Fig. 10: (Continued). 


\section{CONCLUSIONS}

The performance of optical leaky-wave antenna (OLWA) designed using CMOS-compatible silicon platform has been investigated for $1300 \mathrm{~nm}$ operation. Parametric study has been performed to address the effect of geometric parameters on the radiation characteristics of $1550 \mathrm{~nm}$ double-grating antenna (DGA). The simulation results reveal that the $1300 \mathrm{~nm}$ antenna has lower gain and efficiency compared with $1550 \mathrm{~nm}$ counterpart. The relatively lower efficiency result is attributed mainly to the higher input interface reflection and waveguide losses at $1300 \mathrm{~nm}$. Further, the radiation characteristics of the DGA is not the superposition (i.e., linear contribution) of two isolated single-grating antenna (SGA) since the coupling between the two gratings) cannot be neglected since the distance between them $(400 \mathrm{~nm})$ is smaller than the operating wavelength $(1550 \mathrm{~nm})$.

\section{REFERENCES}

[1] J.-M. Fedeli, F. Schrank, E. Augendre, S. Bernab'e, J. Kraft, P. Grosse, and T. ENot, "Photonic-Electronic Integration With Bonding", IEEE Journal of Selected Topics in Quantum Electronics, Vol. 20, No. 4, pp.8201909, July/August 2014.

[2] G. Roelkens, D. Dave Utsav, A. Gassenq, N. Hattasan, Ch. Hu, B. Kuyken, F. Leo, A. Malik, M. Muneeb, E. Ryckeboer, D. Sanchez, S. Uvin, R. Wang, Z. Hens, R. Baets, Y. Shimura, F. Gencarelli, B. Vincent, R. Loo, J. Van, L. Cerutti, J. Rodriguez, E. Tourni'e, X. Chen, M.Nedeljkovic, G. MashaNovich, L. Shen, N. Healy, C. Anna Peacock, X.Liu, R. Osgood,and M. William J. Green, "Silicon-Based Photoniclntegration Beyond theTelecommunication Wavelength Range" IEEEJournal of Selected Topics in Quantum Electronics, Vol. 20, No. 4, pp.8201511, July/August 2014.

[3] D. R. Jackson, P. BurghigNoli, G. Lovat, F. CapoliNo, J. Chen, D. R. Wilton, and A. A. Oliner, "The Fundamental Physics of Directive Beaming at Microwave and Optical Frequencies and the Role of LeakyWaves", Proceedings of the IEEE, Vol. 99, No. 10,PP. 1780-1805, October 2011.

[4] Z. Pan and J. Guo, "Enhanced Optical Absorption and Electric Field Resonance in Diabolo Metal Bar Optical Antennas", Optics Express, Vol. 21, No. 26, PP. 32491-32500, December 2013.

[5] L. Yousefi and A. C. Foster, "Waveguide-Fed Optical Hybrid Plasmonic Patch Nano-Antenna", Optics Express, Vol. 20, No. 16, PP. 18326-18635, July 2012.

[6] S. Campione, C. Guclu, Q. Song, O. Boyraz, and F. Capolino, "An Optical Leaky Wave Antenna with Si Perturbations Inside a Resonator for Enhanced Optical Control of The Radiation”, Optics Express, Vol. 20, No. 19, PP. 21305-21317, September 2012.

[7] C. Guclu, S. Campione, O. Boyraz, and F Capolino, "Theory of a Directive Optical Leaky Wave Antenna Integrated into a Resonator and Enhancement of Radiation Control”, Journal of Lightwave Technology, Vol. 32, NO. 9, PP. 1741-1749, May 2014.

[8] C. Guclu, M. Veysi, O. Boyraz, and F. Capolino, "Optical Leaky-Wave Antenna Integrated in Ring Resonator", arXiv: 1401.7609 (Physic-Optics), Jan 2014.

[9] A. A. Hummadi and R. S. Fyath, "Parametric Study of Silicon-Based Optical Leaky-Wave Antenna", International Journal of Computers and Technology, Vol. 13, No. 9, PP. 4809-4850, July 2014. 


\section{Author's biography}

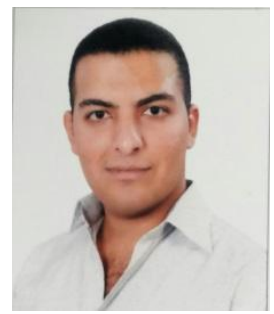

Ali Abbas Hummadi was born in Baghdad, Iraq, in 1988. He received the B.Sc. degree in Laser and Optoelectronics Engineering from Alnahrain University, Iraq in 2010. Currently, he is an M.Sc. researcher in the Laser and Optoelectronics Engineering Department at Alnahrain University. His research interests include Leaky waves, Optical antennas, Optoelectronics, and Communication systems.

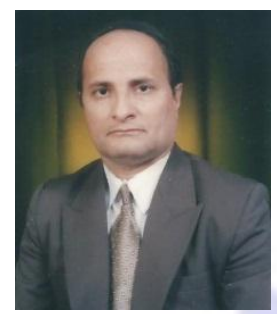

Raad Sami Fyath was born in Maysan, Iraq, in 1954. He received the B.Sc. degree in Electrical Engineering from the University of Basrah, Iraq, in 1976, the M.Sc. degree in Electronics and Communications Engineering from the University of Baghdad, Iraq, in 1987, and the PhD degree in Electronics Engineering from University of WalesBangor, UK, in 1990. Currently, he is a professor of electronics and communications engineering at the College of Engineering, Alnahrain University, Baghdad, Iraq. His research interests include Optical and wireless communications, Optoelectronics, and Nanophotonics. He published more than 100 papers in different scientific journals and conference proceedings. 